\title{
Monoamine oxidase A deficiency
}

INSERM

\section{Source}

INSERM. (1999). Orphanet: an online rare disease and orphan drug data base.

Monoamine oxidase A deficiency. ORPHA:3057

Monoamine oxidase-A deficiency is a very rare recessive $\mathrm{X}$-linked biogenic amine metabolism disorder characterized clinically by mild intellectual deficit, impulsive aggressiveness, and sometimes violent behavior and presenting from childhood. 